\title{
Use of cell therapy as a means of targeting chemotherapy to inoperable pancreatic cancer $\star$
}

\author{
Walter H. Günzburg ${ }^{1 凶}$ and Brian Salmons ${ }^{2}$ \\ ${ }^{1}$ Research Institute for Virology and Biomedicine, University of Veterinary Medicine, Vienna, Austria;

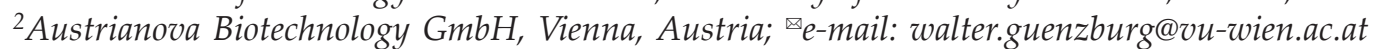

Received: 15 March, 2005; revised: 03 August, 2005; accepted: 12 August, 2005

available on-line: 15 September, 2005

\begin{abstract}
Although approved for the treatment of pancreatic cancer, the chemotherapeutic agent ifosfamide is not an effective therapy for this type of tumour. Ifosfamide must be activated by cytochrome P450 (P450) enzymes in the liver, initially to a short lived intermediate and then to toxic metabolites that are subsequently distributed by the circulatory system. Particularly for pancreatic cancer, this liver-mediated conversion results in relatively high systemic toxicities and poor therapeutic concentrations at the liver-distant site of the tumour. Activation of ifosfamide at the site of the tumour may allow lower doses to be used, while increasing the therapeutic index due to the resultant active concentrations generated locally. A cell-based therapy has been conceived where encapsulated, 293-derived cells genetically modified to overexpress a cytochrome P450 enzyme, are implanted near solid tumours. The cells are encapsulated in polymers of cellulose sulphate in order to provide a means of immunoprotection in vivo as well as to physically constrain them to the vicinity of the tumour. A major advantage of this strategy is that it allows one standard cell line to be applied to all patients and this approach can be extended to the treatment of other tumour types. After proof of principle studies in animal models, a phase I/II clinical trial was initiated in patients with stage III/IV nonresectable pancreatic cancer. Encapsulated cells were angiographically placed into the tumour vasculature of 14 patients and followed by systemic low dose ifosfamide treatment. Angiographic delivery of encapsulated cells proved feasible in all but one patient, and was well tolerated with no capsule or ifosfamide treatment-related adverse events. Four of the treated patients showed tumour regressions after capsule delivery and ifosfamide treatment in computer-tomography scans. The other 10 patients showed no further tumour growth (i.e. stable disease) during 20 weeks observation period. The median life expectancy of the patient collective was extended two fold as compared to age and status matched historical controls, with a 3-fold improvement in one year survival being attained. Evidence for a clinical benefit of the treatment was also obtained on the basis of standard parameters for quality of life. This approach has been evaluated by the European Medicines Evaluation Agency (EMEA) and orphan drug status has been granted. A pivotal clinical trial is now being planned with the help of the EMEA. Taken together, the data from this clinical trial suggest that encapsulated cytochrome P450-expressing cells combined with chemotherapy may be useful for the local treatment of a number of solid tumours and support the performance of further clinical studies of this new treatment.
\end{abstract}

Keywords: cell therapy, encapsulated cells, pancreatic cancer, cytochrome P450, genetically modified cells, chemotherapy

Since its market debut at the end of the 1990's, gemcitabine has rapidly become the treatment of choice for inoperable pancreatic carcinoma (Günzburg et al., 2002; Diaz-Rubio, 2004). Gemcitabine was approved primarily because patients showed an improved quality of life, rather than because of classical parameters such as reduced tumour burden and prolonged survival time. Indeed, recent studies have shown that gemcitabine has only extended the lifespan of patients by a few weeks (Burris et al., 1997). Thus, there is still a need for more efficacious treatments for this devastating

^Presented at the International Review Conference on Biotechnology, Vienna, Austria, November 2004.

Abbreviations: AE, adverse events; CT, computer tomography; CYP2B1, cytochrome P450 isoform 2B1; GDEPT, gene-directed enzyme prodrug therapy; SAE, serious adverse event; SCID, severe combined immunodeficiency; WHO, World Health Organisation. 
form of cancer. This is reflected in the increasing number of novel approaches over the last few years for pancreatic carcinoma both in the preclinical area as well as in clinical trials (Günzburg et al., 2002; Diaz-Rubio, 2004). Strategies have included, but are not limited to, novel chemotherapeutic agents, either alone or in combination chemotherapies (often with gemcitabine), topoisomerase inhibitors that interfere with DNA synthesis, immune response stimulators such as virulizin, granulocyte-macrophage colonystimulating factor, monoclonal antibodies as well as antisense, gene and cell therapy approaches (Günzburg et al., 2002; Diaz-Rubio, 2004).

A common gene therapy approach for the treatment of cancer involves the use of genes encoding enzymes that activate nontoxic drugs, or prodrugs to toxic anti-tumour forms (Table 1). These genes have been named suicide genes, and the combination of gene and prodrug is often referred to as GDEPT (gene-directed enzyme prodrug therapy) (for a review see McKeown et al., 2004). The first and most popular system has been the thymidine kinase gene from herpes simplex virus (Block et al., 1997; Carrio et al., 1999; Howard et al., 2000; Makinen et al., 2000) and, more recently, cytosine deaminase (Shiau et al., 1998; Haack et al., 2000; Kanyama et al., 2001). The gene encoding deoxyribonucleoside kinase has also been shown to function as a suicide gene for pancreatic tumour therapy, at least in cell culture (Zheng et al., 2000). Although impressive, the results with these suicide gene/prodrug combinations were obtained in vitro or in immunocompromised mouse models, whereas in immunocompetent animals cells expressing these nonmammalian enzymes will eventually be eliminated by the host immune system because they are not of mammalian origin.

\section{RESULTS}

We have been developing a cell-based therapy system that utilises a mammalian cytochrome P450 enzyme as a suicide gene in combination with a prodrug that is a commonly used chemotherapeutic agent. The prodrug that we have chosen is ifosfamide, a drug that has proved valuable in the clinic for the treatment of a number of different types of tumours and that initially showed some promise for the treatment of pancreatic carcinoma. In standard

\section{Prodrug \\ Genetically modified cells \\ Activated anti-tumour drug}

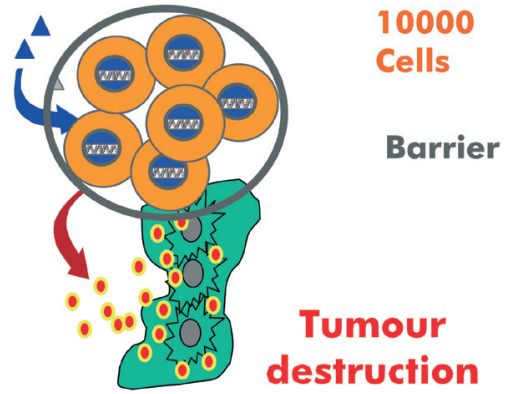

Figure 1. Principle of tumour proximal activation of ifosfamide.

chemotherapy, ifosfamide is first activated in the liver by various cytochrome P450 enzymes, after which the activated transport form, 4-hydroxy-ifosfamide phosphoramide mustard, is distributed by the circulatory system. This short-lived intermediate then decays to the active anti-tumour compounds, phosphoramide mustard and acrolein. Because the halflife of the transport form in plasma is of the order of minutes (Kurowski \& Wagner, 1993), effective therapeutic concentrations cannot be reached without lifethreatening side effects (Cerny et al., 1991; Keizer et al., 1995). Thus, despite a documented anti-tumour effect (Table 2), ifosfamide has not been evaluated further.

One way to circumvent this problem would be to locally activate ifosfamide at the site of the tumour, allowing lower doses of ifosfamide to be applied, thereby resulting in good local cytotoxic activity and minimal side effects. Local activation could be achieved by placing encapsulated human 293 cells stably transfected with a cytochrome P-450 isoform 2B1 (CYP2B1) expression construct at the site of the tumour (Fig. 1). Encapsulation in cellulose sulphate allows allogeneic cells to survive in vivo, because they are physically confined and protected from the host immune system (Löhr et al., 2002; Hauser et al., 2004). Previous experiments had revealed that injection of such encapsulated CYP2B1-expressing cells into pre-established human pancreatic tumours in a nude mouse model resulted in complete tumour regression in about $20 \%$ of mice and a significant anti-tumour effect in the remaining mice (Löhr et al., 1998). These encouraging results suggested that a similar strategy may have a therapeutic effect in patients. A phase I/II clinical trial was designed involv-

Table 1. Suicide gene/prodrug combinations already in use in clinical trials for cancer gene therapy

\begin{tabular}{lll}
\hline Gene & Source & Prodrug \\
\hline Thymidine kinase & Herpes simplex virus & ganciclovir \\
Cytosine deaminase & E. coli & 5-fluorocytosine \\
Nitroreductase & E. coli & 5-(aziridin-1-yl)-2,4-dinitrobenzamide \\
Cytochrome P450 2B1/3A4 & Human, rodent & ifosfamide, cyclophosphamide \\
\hline
\end{tabular}

For further details see http://www.wiley.co.uk/genmed/clinical/ 
Table 2. Clinical experience with ifosfamide in pancreatic cancer

\begin{tabular}{llll}
\hline & Low dose & Medium dose $^{2}$ & Usual dose $^{3}$ \\
\hline Daily & Dose $\left(\mathrm{g} / \mathrm{m}^{2}\right)$ & & $2.0-3.0$ \\
Cycle & 1.6 & $1.8-2.0$ & $\mathrm{nt}$ \\
Total & $<16(10 \mathrm{~d})$ & $9-10(5 \mathrm{~d})$ & $\mathrm{nt}$ \\
\hline Response & $<32$ & $<90$ & nt \\
Stable disease & 0 & $20 \%$ & nt \\
Partial remission & $0-33 \%$ & $56 \%$ & nt \\
Complete & 0 & $4 \%$ & unacceptable \\
\hline Toxicities & & & unacceptable \\
Alopecia & $50 \%$ & $100 \%$ & $>4 \%$ \\
Haematotoxicity & $50 \%$ & $100 \%$ & $>50 \%$ \\
Haemorrhagic cystitis & $0 \%$ & $4 \%$ & unacceptable \\
Fatigue & $50 \%$ & $100 \%$ & \\
Nausea/vomiting & $75 \%$ & not known & \\
\hline
\end{tabular}

${ }^{1}$ (Wils et al., 1993; Keizer et al., 1995); ${ }^{2}$ (Gad-el-Mawla \& Ziegler, 1981; Gad-el-Mawla, 1986); ${ }^{3}$ Concentration used for other tumour types. This concentration has not been tested for pancreatic cancer; nt, indicates not tested

ing patients with inoperable pancreatic carcinoma to assess the feasibility, safety, and tolerability of this new treatment modality (Löhr et al., 1999). During the planning of the clinical trial it was decided not to directly inject capsules into the tumour to avoid the possibility of generating needle tract metastases. Another possible route of delivery of the capsules would be via the blood supply. Intra-arterial angiographic placement of microencapsulated cells into pig pancreas was shown to be feasible and well tolerated (Kröger et al., 1999; Löhr et al., 2003) and thus was chosen as the route of delivery. Each patient enrolled in the trial received 300 cellulose sulphate capsules with an average diameter of $0.8 \mathrm{~mm}$, each containing $10^{4}$ cells, by angiographic placement (day 0 ) into a suitable artery feeding a primary, inoperable tumour (stage III/IV). Subsequently, each patient received low-dose ( $1 \mathrm{~g} / \mathrm{m}^{2}$ body surface) ifosfamide (Holoxan) on days 2-4 and 23-25 after capsule implantation (Löhr et al., 1999).

A total of 17 patients were enrolled in the study and 14 of the 17 patients received encapsulated cells delivered by a supraselective catheter that was inserted into an appropriate artery leading into the tumour. Two of the 3 patients who were not treated had to be excluded from the study because they developed severe infections before the trial was initiated. The third patient did not receive encapsulated cells because an unusual blood vessel architecture did not allow successful angiographic placement. Typically, a transient spasm could be observed immediately after instillation of the encapsulated cells but the vessel quickly returned to normal and patency was observed. Moreover, follow-up angiography of the targeted vessels 20 weeks after capsule instillation revealed no or only minor changes to the vessels, suggesting the possibility of administration of a further dose of encapsulated cells.
Although 11 serious adverse events (SAEs) were recorded in 7 of the patients, none of these SAEs were due to treatment with encapsulated cells or ifosfamide and were clearly attributable to progression of the underlying disease. Moreover, there was no evidence of pancreatitis or allergic responses at any time during the study period. Documented adverse events (AEs) were most often due to pain, underlying disease, or an aggravated health condition, with the possible exception of increased lipase activity which was observed in 1 patient on day 15 after instillation.

The chemotherapy regimen was also well tolerated, with litle toxicity beyond grade II being detected. Plasma levels of ifosfamide were measured and 30-60 min after administration shown to be in the range of 100-200 $\mu \mathrm{mol} / \mathrm{l}$ (Lohr et al., 2003). Thus, in summary, the phase I related goals of the study were achieved in that no specific treatment-related risk could be demonstrated in the 14 patients treated.

As well as safety and tolerability, the efficacy of the treatment was also monitored. The size of the primary tumour was measured before starting the treatment and set at $100 \%$. The tumour size was then measured by computer tomography (CT) scans at weeks 10 and 20 post-treatment and the size related to the pre-treatment value. Interestingly, none of the tumours showed any significant growth during the whole observation period in any of the treated patients.

Indeed, in 2 of the 14 patients a reduction of $50 \%$ or more (i.e. a partial response) was documented (Table 2). A further 2 patients showed a minor response, i.e. a tumour reduction of $25-50 \%$, with the other 8 patients showing stable disease. Two of the patients were not available for the CT analysis at week 10 . 
Table 3. Tumour response of patients $(n=14)$ receiving encapsulated cells and low dose ifosfamide

\begin{tabular}{lll}
\hline & $\mathrm{n}$ & Percentage \\
\hline Partial response (PR) & 2 & $14.3 \%$ \\
Minimal response (MR) & 2 & $14.3 \%$ \\
Total responders (PR + MR) & 4 & $28.6 \%$ \\
Stable disease & 8 & $71.4 \%$ \\
Progressive disease & 0 & $0 \%$ \\
No follow-up & 2 & $14.3 \%$ \\
\hline
\end{tabular}

The median survival time of the patients treated in this study was 40 weeks from the time of diagnosis. This compares favourably both with respect to the 20 weeks survival achieved by an ageand status-matched control group consisting of 35 stage III-IV patients from the same study centre as well as with published data on patient survival after gemcitabine treatment (Burris et al., 1997). The average survival time of the treatment group was more than 45 weeks compared to 30 weeks for the control group. The percentage of patients surviving for 1 year or more was $35.7 \%$, compared to $11.1 \%$ for the control group. One of the patients from the treated group survived almost two years. Within the 20 week study period, 3 patients died of disease progression (on days 9, 85, and 132). The patient who died on day 9, as a result of recurrent pulmonary embolism, underwent post-mortem examination. This patient had a history of pulmonary embolism, even before commencing the trial and no capsules could be found in the lesions. Macroscopic examination of the tumour in this patient revealed remarkable tumour necrosis and this was confirmed by histological examination. Necrosis associated with the encapsulated cell/ifosfamide therapy has also been observed in the mouse model system (Löhr et al., 1998) and, at least for some cell types in cell culture, seems to be the mechanism of cell killing (Karle et al., 2001). Beyond the 20 -week study period, a further 10 patients died. The 3 patients who died during the trial and 3 of the patients who died after the 20-week observation had metastases in the liver before commencement of the trial, which is know to be associated with a poorer prognosis. One patient who died at week 53 (i.e., outside the study period) was examined by post-mortem, and a wide-spread pancreatic tumour was confirmed.

An integrative score of clinical benefit was calculated in which a stable condition was deemed

Table 4. Survival data a clinical benefit. In a worst case scenario (any worsening means no benefit), seven patients (50\%) experienced a clinical benefit, three were neutral $(21.4 \%$; benefits were offset by impairments), and four patients (including those dying before the average survival time) had no clinical benefit (28.6\%). In a best case scenario (clinically relevant worsening required), ten patients $(71.4 \%)$ had clinical benefit, two patients showed no benefit but no deterioration (14.3\%), and two patients had definitely no benefit. None of the patients registered an increase in pain medication in terms of either analgesic dosage or WHO scale.

\section{DISCUSSION}

Chemotherapy has previously only been marginally effective for the treatment of pancreatic carcinoma, despite the introduction of new cytotoxic agents such as gemcitabine (Carmichael et al., 1996; Storniolo et al., 1999). Gemcitabine acts by multiple mechanisms, including inhibition of ribonucleoside diphosphate reductase, dCMP deaminase, and dCTP incorporation into DNA and RNA, thereby disrupting DNA synthesis and causing apoptosis (Rieger et al., 1999). Clinical responses after treatment with gemcitabine are achieved in $5.4-11 \%$ of pancreatic cancer patients, with a median survival time of between 5.6 and 6.3 months (Casper et al., 1994; Carmichael et al., 1996; Burris et al., 1997). The general median survival of patients with pancreatic carcinoma is only around 4 months so the improvement afforded by gemcitabine treatment is at best modest. New treatment modalities for pancreatic cancer are thus desperately needed. The chemotherapeutic agent ifosfamide requires activation in the liver. In the late 1970's and early 1980's, ifosfamide was used for the chemotherapy of pancreatic cancer and gave response rates of up to 30\% (Loehrer et al., 1985; Ajani et al., 1988; Cerny et al., 1991; Keizer et al., 1995). However, relatively high systemic concentrations were required and this was associated with significant side effects, particularly in elderly patients (Loehrer et al., 1985).

A number of preclinical studies, using tumour cells of nonpancreatic and pancreatic cancer origin, have shown the utility of the local expression of cytochrome P450 enzymes, in combination with oxazaphosphorines like ifosfamide or cyclophosphamide (Wei et al., 1994; Chen \& Waxman, 1995).

\begin{tabular}{lllll}
\hline & $\mathrm{n}$ & Mean survival & Median survival & 1 year survival (\%) \\
\hline Control & 36 & $>30$ weeks & 20 weeks & $11 \%$ \\
Encapsulated cells + ifosfamide & 14 & $>45.4$ weeks & 40 weeks & $36 \%$ \\
Gemzar $^{1}$ & 63 & & 28 weeks & $18 \%$ \\
\hline
\end{tabular}

${ }^{1}$ Data from pivotal phase III trial (Burris et al., 1997) 
Most previous studies, however, report that the cytochrome P450 gene was introduced directly into the tumour cells before the establishment of tumours in nude or SCID mice, followed by oxazaphosphorine treatment. Thus, although these studies convincingly demonstrate proof of principle, they represent an artificial system that is not clinically applicable.

Encapsulation of genetically modified cells is a powerful technology that allows cells to be safely implanted. Encapsulation of cells in biocompatible polymers protects them from the host immune system and localises them to the site where their action is required (Hauser et al., 2004) (Fig. 1). We have previously reported that the encapsulation of cells genetically modified to overexpress cytochrome P450 and the intratumoral injection of these encapsulated into preformed human pancreatic tumours in nude mice, followed by ifosfamide treatment, results in tumour reductions (Löhr et al., 1998). Similar results were obtained when these encapsulated cells were injected into mammary tumours in two immunocompetent strains of mice (Kammertöns et al., 2000; Uckert et al., 2003). Based upon all of this data, we reasoned that a similar approach might prove feasible in humans. Local intra-tumoral activation holds the promise of good efficacy coupled with low systemic side effects due to reduced concentration of the chemotherapeutic agent. In contrast to mouse model studies, it was planned to deliver the encapsulated cells via blood vessels leading to the tumour since direct intra-tumoral injection may cause the formation of needle track metastases as well as causing unnecessary bleeding, both of which can potentially seed metastatic cells. The pancreas is located deep in the retroperitoneum, making repeated transcutaneous injections difficult. Delivery via the pancreatic duct is also limited in the majority of tumours due to occlusion. In contrast, interventional angiography is a relatively noninvasive approach that is becoming popular for the treatment of non-resectable tumours (Dondelinger, 1999). Thousands of smaller solid microspheres delivered by angiography have been used to deliberately occlude blood vessels leading to the primary and metastatic hepatic masses in previous studies (Trinchet, 1995; Talamonti et al., 1998). This contrasts with our study in which only 300 cell-filled capsules were delivered, without causing blood vessel occlusion (although a momentary spasm lasting a few minutes was observed) (Löhr et al., 2001; 2003). This was confirmed in experiments where blood flow was measured in isolated perfused porcine pancreas that had received encapsulated cells (Löhr et al., 2003). That the mode of action is not simply blood vessel occlusion is also supported by the finding that a therapeutic effect was obtained after direct injection of encapsulated cells into tumours followed by ifosfamide administration in two different mouse tumour model systems (Karle et al., 1998; Löhr et al.,
1998; Kammertöns et al., 2000). It seems likely that arterial blood flow is an important requirement in our study both to ensure adequate survival of the encapsulated CYP2B1 cells as well as to allow good intra-tumoral diffusion of the active metabolites.

The encapsulation material consists of inert cellulose polymers (Dautzenberg et al., 1999; Löhr et al., 2002), and there was no evidence for an allergic response or inflammatory reaction either to the material or to the genetically modified cells. Treatmentrelated serious adverse events were not observed during the study period. The ifosfamide dose was well tolerated, as was the capsule instillation, which could be performed under local anaesthesia on average over a $15-\mathrm{min}$ period. Thus the primary objectives of the study, namely the evaluation of the safety and tolerability of the treatment, have been met.

In addition, all the treated patients showed a stabilization of tumour size and 4/14 (28\%) showed a reduction in tumour size of more than $25 \%$, in contrast to the normal progression of the disease in which the tumour mass continues to grow. The ability to effect a reduction in tumour size may allow originally non-resectable tumours to become eligible for surgical resection. Even if subsequent surgery is still not feasible, a decrease in the primary tumour size is of clinical benefit in terms of increased survival time and clinical response data such as decreased pain. This benefit was confirmed in our study in which an increased median survival time after diagnosis of more than 40 weeks and an increased quality of life including no requirement for increased pain medication was noted. Although this is a phase I/II study with a relatively small patient collective, these results compare favourably with those obtained with gemcitabine, in which a median survival of about 25 weeks was reported (Burris et al., 1997; Storniolo et al., 1999). Even more impressive was the increase in the 1-year survival rate from $11.1 \%$ in the control group to $35.7 \%$ in the treated group. The 1-year survival rate for gemcitabine in a pivotal phase III trial was 18\% (Burris et al., 1997).

New treatment strategies for pancreatic cancer may qualify for orphan drug status since the incidence is relatively low. The use of encapsulated cells overexpressing cytochrome P450 has been designated an orphan medicinal product by the European Medicines Evaluation Agency and a pivotal phase III clinical trial is now planned for 2006 with a view to market approval, should the data warrant it.

Even if encapsulated cells plus ifosfamide is efficacious enough in a phase III trial to be approved as a marketable product for primary pancreatic cancer, it seems unlikely that the treatment described here will affect metastases. The use of encapsulated cells producing retroviral vectors that can seek out and deliver cytochrome P450 to metastatic cells may 
represent a viable strategy for this purpose. One prerequisite for this approach has been met in that encapsulated retroviral vector producing cells have been reported to be able to infect surrounding cells after transplantation (Saller et al., 2002). The use of infection and/or expression targeted retroviral vectors (Salmons \& Gunzburg, 1993; Hlavaty et al., $2004 a ; 2004 b)$ may contribute further to the success of such an approach.

In summary, we report the feasibility, tolerability, and safety of intra-tumour placement of CYP2B1-expressing encapsulated cells combined with low doses of systemic ifosfamide as a means to treat local, solid tumours such as pancreatic cancer without major side effects. More importantly, considering the circumstances of a phase I/II study, a substantial anti-tumour effect on the primary pancreatic tumour was observed. Clearly, however, there is room for optimization of the treatment, for example, by multiple administrations of ifosfamide and, later, possibly capsules.

\section{Acknowledgements}

The authors would like to thank Walter Tabotta and Eva Prieschl-Grassauer for their help and support. The authors acknowledge the support of the staff of the University of Rostock (Germany); Bavarian Nordic (Munich, Germany); the Vienna General Hospital (AKH, Vienna, Austria); Austrianova Biotechnology (Vienna, Austria), and the University of Veterinary Medicine (Vienna, Austria).

\section{REFERENCES}

Ajani JA, Abbruzzese JL, Goudeau P, Faintuch JS, Yeomans AC, Boman BM, Nicaise C, Levin B (1988) Ifosfamide and mesna: marginally active in patients with advanced carcinoma of the pancreas. J Clin Oncol 6: 1703-1707.

Block A, Chen SH, Kosai K, Finegold M, Woo SL (1997) Adenoviral-mediated herpes simplex virus thymidine kinase gene transfer: regression of hepatic metastasis of pancreatic tumors. Pancreas 15: 25-34.

Burris HA, Moore MJ, Andersen J, Green MR, Rothenberg ML, Modiano MR, Cripps MC, Portenoy RK, Storniolo AM, Tarassoff P, Nelson R, Dorr FA, Stephens CD, von Hoof DD (1997) Improvements in survival and clinical benefit with gemcitabine as first-line therapy for patients with advanced pancreatic cancer: a randomized trial. I Clin Oncol 15: 2403-2413.

Carmichael J, Fink U, Russell RCG, Spittle MF, Harris AL, Spiessi G, Blatter J (1996) Phase II study of gemcitabine in patients with advanced pancreatic cancer. $\mathrm{Br} \mathrm{J} \mathrm{Can}$ cer 73: 101-105.

Carrio M, Romagosa A, Mercade E, Mazo A, Nadal M, Gomez-Foix A-M, Fillat, C (1999) Enhanced pancreatic tumor regression by a combination of adenovirus and retrovirus-mediated delivery of the herpes simplex virus thymidine kinase gene. Gene Ther 6: 547-553.

Casper ES, Green MR, Kelsen DP, Heelan RT, Brown TD, Flombaum CD, Trochanowski B, Tarassoff PG (1994)
Phase II trial of gemcitabine (2,2'-difluorodeoxycytidine) in patients with adenocarcinoma of the pancreas. Invest New Drugs 12: 29-34.

Cerny T, Martinelli G, Goldhirsch A, Terrier F, Joss R, Fey MF, Brunner KW, Kupfer A (1991) Continuous 5-day infusion of ifosfamide with mesna in inoperable pancreatic cancer patients: a phase II study. I Cancer Res Clin Oncol 117: S135-S138.

Chen L, Waxman DJ (1995) Intratumoral activation and enhanced chemotherapeutic effect of oxazaphosphorines following cytochrome P-450 gene transfer: development of a combined chemotherapy/cancer gene therapy strategy. Cancer Res 55: 581-589.

Dautzenberg H, Schuldt U, Grasnick G, Karle P, Müller P, Löhr M, Pelegrin M, Piechaczyk M, von Rombs K, Günzburg WH, Salmons B, Saller RM (1999) Development of cellulose sulphate based polyelectrolyte complex microcapsules for medical applications. Ann NY Acad Sci USA 875: 46-63.

Diaz-Rubio E (2004) New chemotherapeutic advances in pancreatic, colorectal, and gastric cancers. Oncologist 9: 282-294.

Dondelinger R (1999) Advances in abdominal interventional radiology. Lancet 353: SI15-SI18.

Gad-el-Mawla N (1986) Ifosfamide in advanced pancreatic cancer. A 5-year experience. Cancer Chemother Pharmacol 18 (Suppl 2): 55-56.

Gad-el-Mawla N, Ziegler JL (1981) Ifosfamide treatment of pancreatic cancer. Cancer Treat Rep 65: 357-358.

Günzburg WH, Lohr M, Salmons B (2002) Novel treatments and therapies in development for pancreatic cancer. Expert Opin Investig Drugs 11: 769-786.

Haack K, Linnebacher M, Eisold S, Zoller M, von Knebel Doeberitz M, Gebert J (2000) Induction of protective immunity against syngeneic rat cancer cells by expression of the cytosine deaminase suicide gene. Cancer Gene Ther 7: 1357-1364.

Hauser O, Prieschl-Grassauer E, Salmons B (2004) Encapsulated, genetically modified cells producing in vivo therapeutics. Curr Opin Mol Ther 6: 412-420.

Hlavaty J, Portsmouth D, Stracke A, Salmons B, Günzburg WH, Renner M (2004a) Effects of sequences of prokaryotic origin on titre and transgene expression in retroviral vectors.

Hlavaty J, Stracke A, Klein D, Salmons B, Günzburg WH, Renner M (2004b) Multiple modifications allow high titer, tissue-specific retroviral vector production. J Virol 78: 1384-1392.

Howard BD, Boenicke L, Scniewind B, Henne-Bruns D, Kalthoff H (2000) Transduction of human pancreatic tumor cells with vesicular stomatitis virus G-pseudotyped retroviral vectors containing a herpes simplex virus thymidine kinase mutant gene enhances bystander effects and sensitivity to ganciclovir. Cancer Gene Ther 7: 927-938.

Kammertöns T, Gelbmann W, Karle P, Saller R, Salmons B, Günzburg WH, Uckert W (2000) Combined chemotherapy of murine mammary tumors by local activation of the prodrugs ifosfamide and 5-fluorocytosine. Cancer Gene Ther 7: 629-636.

Kanyama H, Tomita N, Yamano T, Aihara T, Miyoshi $\mathrm{Y}$, Ohue M, Sekimoto M, Sakita I, Tamaki Y, Kaneda Y, Senter PD, Monden M (2001) Usefulness of repeated direct intratumoral gene transfer using hemagglutinating virus of Japan-liposome method for cytosine deaminase suicide gene therapy. Cancer Res 61: 14-18.

Karle P, Müller P, Renz R, Jesnowski R, Saller RM, von Rombs K, Nizze H, Liebe S, Günzburg WH, Salmons B, Löhr M (1998) Intratumour injection of encapsulated cells producing an ifosfamide activating cytochrome 
P450 for targeted chemotherapy. Adv Exp Med Biol 451: 97-106.

Karle P, Renner M, Salmons B, Günzburg WH (2001) Necrotic, rather than apoptotic, cell death caused by cytochrome P450 activated ifosfamide. Cancer Gene Ther 8: 220-230.

Keizer HJ, Ouwerkerk J, Welvaart K, van der Velde CJH, Cleton FJ (1995) Ifosfamide treatment as a 10-day continuous intravenous infusion. I Cancer Res Clin Oncol 121: 297-302.

Kröger JC, Bergmeister H, Hoffmeyer A, Ceijna M, Karle $\mathrm{P}$, Saller R, Schwendenwein I, von Rombs K, Liebe S, Günzburg WH, Salmons B, Hauenstein K-H, Losert U, Löhr M (1999) Intra-arterial instillation of microencapsulated cells in the pancreatic arteries in pig. Ann NY Acad Sci USA 880: 374-378.

Kurowski V, Wagner T (1993) Comparative pharmacokinetics of ifosfamide, 4-hydroxyifosfamide, chloroacetaldehyde, and 2- and 3-dechloroethylifosfamide in patients on fractionated intravenous ifosfamide therapy. Cancer Chemother Pharmacol 33: 36-42.

Loehrer PJ, Williams SD, Einhorn LH, Ansari R (1985) Ifosfamide: an active drug in the treatment of adenocarcinoma of the pancreas. J Clin Oncol 3: 367-372.

Löhr M, Müller P, Karle P, Stange J, Mitzner S, Jesnowski R, Nizze H, Nebe B, Liebe S, Salmons B, Günzburg WH (1998) Targeted chemotherapy by intratumour injection of encapsulated cells engineered to produce CYP2B1, an ifosfamide activating cytochrome P450. Gene Therapy 5: 1070-1078.

Löhr JM, Bago ZT, Bergmeister H, Ceijnka M, Freund M, Gelbmann W, Günzburg WH, Jesnowski R, Hain J, Hauenstein K, Henninger W, Hoffmeyer A, Karle P, Kröger J-C, Kundt G, Liebe S, Losert U, Müller P, Probst A, Püschel K, Renner M, Renz R, Saller R, Salmons B, Schuh M, Schwendenwein I, von Rombs K, Wagner T, Walter I (1999) Cell therapy using microencapsulated 293 cells transfected with a gene construct expressing CYP2B1, an ifosfamide converting enzyme, instilled intra-arterially in patients with advanced stage pancreatic carcinoma: a phase I/II study. J Mol Med 77 393-398.

Lohr M, Hoffmeyer A, Kroger J-C, Freund M, Hain J, Holle A, Karle P, Knofel WT, Liebe S, Muller P, Nizze $\mathrm{H}$, Renner M, Saller RM, Wagner T, Hauenstein K, Gunzburg WH, Salmons B (2001) Microencapsulated, cellmediated treatment of inoperable pancreatic carcinoma. Lancet 357: 1591-1592.

Löhr M, Saller RM, Salmons B, Gunzburg WH (2002) Microencapsulation of genetically engineered cells for cancer therapy. Methods Enzymol 346: 603-618.

Löhr JM, Kröger J-C, Hoffmeyer A, Benz S, Müller P, Saller R, Nizze H, Klöppel G, Bergmeister H, Bago Z, Günzburg WH, Karle P, Obermaier R, Probst A, Renner M, Salmons B, Schwendenwein I, von Rombs K, Wiessner R, Losert U, Wagner T, Hauenstein K (2003) Intra-arterial instillation of microencapsulated, ifosfamide activating cells in the pig pancreas for chemotherapeutic targeting. Pancreatology 3: 55-63.
Lohr M, Hoffmeyer A, Kroger J-C, Freund M, Gunzburg WH, Hain J, Holle A, Knofel WT, Liebe S, Muller P, Nizze H, Renner M, Saller RM, Salmons B, Wagner T, Hauenstein K (2003) Safety, feasibility and clinical benefit of localized chemotherapy using microencapsulated cells for inoperable pancreatic carcinoma in a phase I/II trial. Cancer Therapy 1: 121-131.

Makinen K, Loimas S, Wahlfors J, Alhava E, Janne J (2000) Evaluation of herpes simplex thymidine kinase mediated gene therapy in experimental pancreatic cancer. $J$ Gene Med 2: 361-367.

McKeown SR, Ward C, Robson T (2004) Gene-directed enzyme prodrug therapy: a current assessment. Curr Opin Mol Ther 6: 421-435.

Rieger J, Durka S, Streffer J, Dichgans J, Weller M (1999) Gemcitabine cytotoxicity of human malignant glioma cells: modulation by antioxidants, Bcl-2 and dexamethasone. Eur J Pharmacol 365: 301-308.

Saller RM, Indraccolo S, Coppola V, Esposito G, Stange J, Mitzner S, Heinzmann U, Amadori A, Salmons B, Gunzburg WH (2002) Encapsulated cells producing retroviral vectors for in vivo gene transfer. I Gene Med 4: $150-160$.

Salmons B, Gunzburg WH (1993) Targeting of retroviral vectors for gene therapy. Human Gene Therapy 4: 129141.

Shiau A-L, Yang H-M, Wu P, Wu C-L (1998) Provision of postive and negative selections in retroviral vectors containing the cytosine deaminase gene. Gene Therapy 5: 1571-1574

Storniolo AM, Enas NH, Brown CA, Voi M, Rothenberg ML, Schilsky R (1999) An investigational new drug treatment program for patients with gemcitabine: results for over 3000 patients with pancreatic carcinoma. Cancer 85: 1261-1268.

Talamonti M, Tellez C, Benson A (1998) Local-regional therapy for metastatic liver tumors. Cancer Treat Res. 98: 172-199.

Trinchet JC (1995) A comparison of lipiodol chemoembolization and conservative treatment for unresectable hepatocellular carcinoma. N Engl J Med 332: 1256-1261.

Uckert W, Salmons B, Beltinger C, Günzburg WH, Kammertöns T (2003) Combination suicide gene therapy. Methods Mol Med 90: 345-352.

Wei MX, Tamiya T, Chase M, Boviatsis EJ, Chang TKH, Kowall NW, Hochberg FH, Waxman DJ, Breakefield XO, Chiocca EA (1994) Experimental tumor therapy in mice using the cyclophosphamide-activating cytochrome P450 2B1 gene. Human Gene Therapy 5: 969 978.

Wils JA, Kok T, Wagener DJT, Francois E, Selleslags J, Duez N (1993) Phase II trial with ifosfamide in pancreatic cancer. Eur J Cancer 29A: 290.

Zheng X, Johansson M, Karlsson A (2000) Retroviral transduction of cancer cell lines with the gene encoding Drosophila melanogaster multisubstrate deoxyribonucleoside kinase. I Biol Chem 275: 39125-39129. 